\title{
O que explica a falta de professores nas escolas brasileiras?
}

\author{
What explains the lack of teachers in Brazilian schools?
}

Lo que explica la falta de profesores en las escuelas brasileñas?

\section{José Marcelino de Rezende Pinto ${ }^{1}$}

\section{Resumo}

É comum constatar no dia a dia das escolas a ausência de professores habilitados para atuar em um conjunto de disciplinas. A decorrência natural dessa constatação, do ponto de vista das políticas públicas, é a ampliação da oferta de cursos de formação de professores, inclusive nas modalidades de Educação a Distância (EAD). Este estudo teve como objetivo avaliar se a ausência de professores nas escolas decorre da falta de professores formados, ou do desinteresse dos licenciados em lecionar. Tendo por base os dados de concluintes nos cursos de licenciatura nos últimos 20 anos, levantados pelo INEP, e considerando uma estimativa de demanda de professores por disciplina, constata-se que, com exceção da disciplina de física, existem professores habilitados em número mais do que suficiente para assumir as turmas existentes, concluindo-se que se trata essencialmente de um problema de falta de atratividade da carreira docente. Analisando-se as vagas oferecidas, conclui-se também que somente a oferta pública seria plenamente suficiente para atender a demanda em todos os componentes curriculares, bastando, para tanto desenvolver políticas que estimulassem o preenchimento dessas vagas e a conclusão com êxito dos ingressantes.

Palavras-chave: Políticas educacionais; Trabalho docente; Falta de professores; Atratividade.

\begin{abstract}
It is common to observe dayly in Brazilian schools the lack of enabled teachers of several school subjects. The natural action to face this problem, from the standpoint of public policy, is expanding the supply of training courses for teachers, including those in the mode of Distance Learning (ODL). This study aimed to evaluate whether the absence of teachers in schools due to lack of trained teachers, or the disinterest of graduates in teaching. Based on the data of undergraduate programs in the last 20 years, raised by INEP, and considering an estimate of demand for teachers by subject, what appears is that, with the exception of the discipline of physics, there are graduated teachers more than enough to take the existing class, concluding that this is essentially a problem of lack of attractiveness of the teaching career. Analyzing the positions offered, this work also shows that only the offer made by government would be sufficient to meet demand in all curriculum components, being necessary just develop policies that would stimulate both filling these vacancies and the successful completion of the entrants.
\end{abstract}

Keywords: Educational policies; Teaching; Shortage of teachers; Attractiveness. 


\section{Resumen}

Es común observar que en el día a día las escuelas carecen de docentes habilitados para actuar en una serie de asignaturas. El resultado natural de este hallazgo, desde el punto de vista de la política pública, és que se está ampliando la oferta de cursos de formación para los profesores, incluyendo las modalidades de Educación a Distancia (EAD). Este estudio tuvo como objetivo evaluar si la ausencia de los maestros en las escuelas és debido a la falta de maestros capacitados, o la falta de interés de los graduados en la enseñanza. Con base en los datos de los graduados en programas de pregrado en los últimos 20 años, planteadas por INEP, y dado una estimación de la demanda de los maestros por asignatura, parece que, con la excepción de la disciplina de física, hay maestros calificados en números más que lo suficiente para la demanda existente, llegando a la conclusión de que este es esencialmente un problema de falta de atractividad de la carrera docente. Con el análisis de las plazas ofertadas, se deduce también que sólo la oferta pública sería totalmente suficiente para satisfacer la demanda en todos las asignaturas del plan de estúdios básico nacional, sólo tieniendo que desarrollar políticas que estimulen tanto llenar estas vacantes como garantizar la finalización con éxito de los participantes.

Palabras-clave: Políticas educativas; Enseñanza; Escasez de maestros; Atractividad.

O problema da falta de professores é tema recorrente na mídia e na pauta dos gestores públicos que planejam e executam as políticas educacionais. Afinal, para qualquer rede de ensino que olhemos, logo constatamos a ausência de professores habilitados. A questão que fica é: faltam professores formados (licenciados) em número suficiente, ou aqueles habilitados buscam outras atividades remuneradas em função da pequena atratividade da profissão?

Um primeiro levantamento desta questão foi feito em estudo do qual participei (SAMPAIO et alli, 2002) feito pelo Instituto Nacional de Estudos e Pesquisas Educacionais Anísio Teixeira (INEP) e que tendo por base o número de licenciados formados na década de 1990 apontava para a falta de licenciados em número suficiente a partir de uma estimativa de demanda. A pesquisa também já apontava para um grande crescimento na oferta de vagas nas licenciaturas. Um dos resultados deste estudo foi a criação pelo Conselho Nacional de Educação de uma comissão especial, presidida por Antônio Ibañes Ruiz, tendo como relator Mozart Neves Ramos, contando ainda com a presença de Murílio de Avellar Hingel que produziu o relatório intitulado Escassez de professores no Ensino Médio (CNE, 2007) reforçando a necessidade de formação de professores, em especial nas áreas de Física e Química.

Com este trabalho pretende-se retomar o tema, tendo em vista, inclusive, a enorme ampliação da oferta de educação superior no Brasil nos últimos anos, em especial pelo setor privado e, em particular, na modalidade EAD (Educação a Distância), com razoável subsídio do governo federal, seja via Programa Universidade para Todos - Prouni, seja via Fundo de Financiamento Estudantil - FIES.

O gráfico 1 dá uma dimensão clara do que foi a expansão de vagas de licenciatura na modalidade EAD. 
Gráfico 1 Evolução das vagas, ingressantes e concluintes em cursos de licenciatura na modalidade EAD 2000-2009

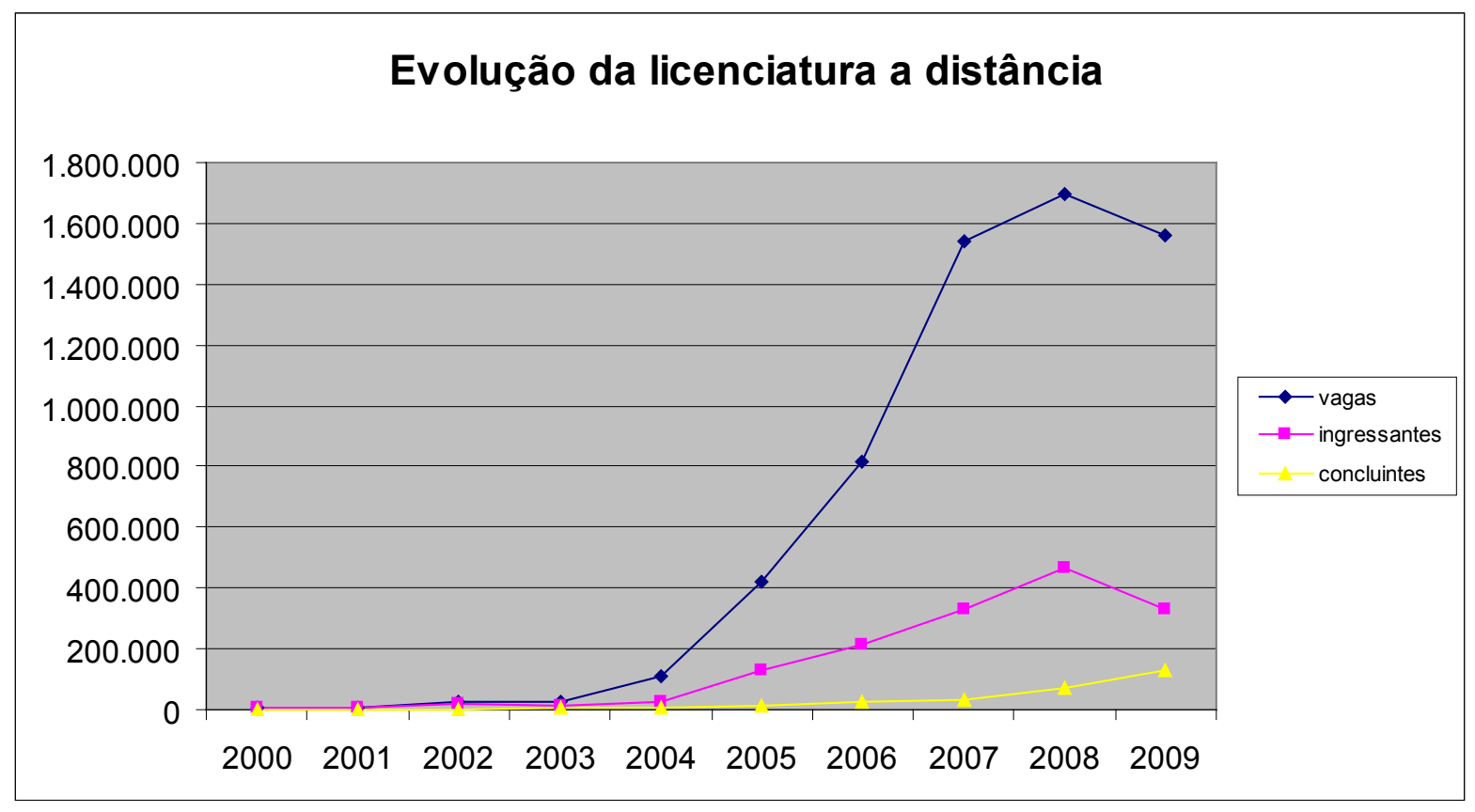

Fonte: INEP/MEC (Censo da Educação Superior)

Os dados do gráfico 1 indicam que não obstante a enorme expansão de vagas de 2003 a 2009, atingindo em 2008, o patamar de 1,7 milhões, boa parte das mesmas não foi preenchida e o número de concluintes ainda é relativamente pequeno.

Essa explosão das vagas na EAD ajuda a entender também a queda na procura nas licenciaturas presenciais que é mostrada no gráfico 2.

Gráfico 2 Evolução do número de inscritos por vaga e de ingressantes por vaga nos cursos de licenciatura presencial 2000-2009

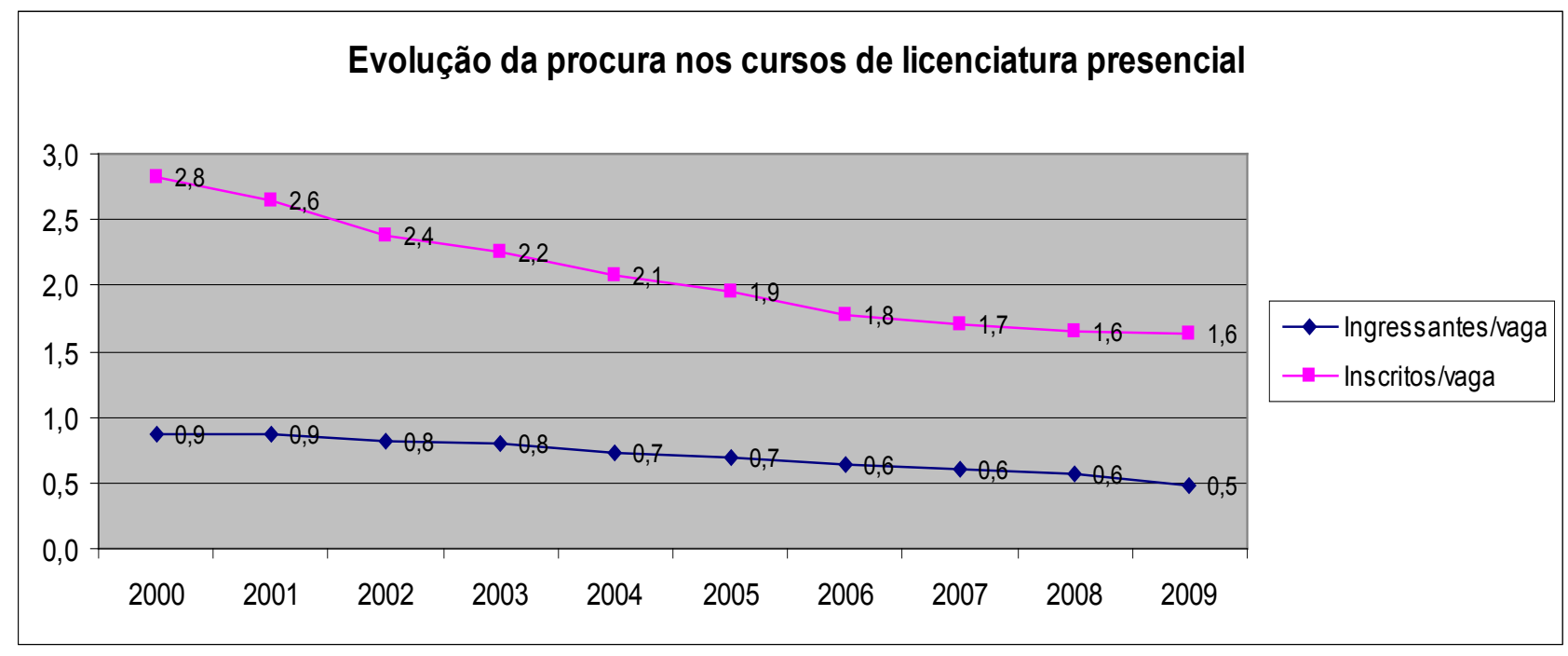

Fonte: INEP/MEC (Censo da Educação Superior) 
Como se constata o país chegou a 2009 com uma vaga ociosa para cada vaga ocupada em cursos presenciais de licenciatura. Esse fato tem reflexos claros sobre o perfil dos alunos que ingressam nesses cursos. Ou seja, independentemente do desempenho em processos seletivos, ao menos no que se refere às instituições privadas, quem se inscreveu em curso de licenciatura teve sua vaga garantida. O número de vagas ociosa, a maioria em instituições privadas de ensino, explica também a pressão por recursos do FIES.

\section{Estimando a demanda}

A tabela 1 apresenta os dados de matrícula e de turmas para o ano de 2012, primeiro passo para se aquilatar a demanda.

Tabela 1: Matrículas e número de turmas por etapa - 2012, Brasil

\begin{tabular}{|c|c|c|c|c|c|}
\hline & Creche & Pré-escola & $\begin{array}{c}\text { Ens.Fund. } \\
\text { Anos Iniciais }\end{array}$ & $\begin{array}{c}\text { Ens.Fund. Anos } \\
\text { finais }\end{array}$ & $\begin{array}{c}\text { Ensino Médio e Ed. } \\
\text { profissional }\end{array}$ \\
\hline Matrículas & 2541 & 4755 & 17074 & 15104 & 10.468 \\
\hline Turmas & 164 & 262 & 791 & 616 & 343 \\
\hline Mat/turma & 15,5 & 18,1 & 21,6 & 24,5 & 30,5 \\
\hline
\end{tabular}

Fonte: Censo Escolar 2012

Obs 1: Inclui as modalidades EJA e Ed. Especial

Obs 2: Os dados de matrícula e turmas estão sintetizados em milhares (x1000)

Para aferir a demanda no caso da pré-escola e anos iniciais do ensino fundamental, estima-se, em princípio, um professor por turma, tendo em vista que predomina a jornada em tempo parcial. No caso de creche, estimamse dois professores por turma, pois predomina a jornada em tempo integral. Cabe lembrar que para estas etapas da educação básica, a lei (LDB) não exige formação em nível superior, mas entende-se que esta escolaridade é fundamental para uma progressiva melhora da qualidade do ensino, como, aliás, aponta o Plano Nacional de Educação recentemente aprovado (lei no 13.005/2014). Feitas essas considerações, estima-se uma demanda de 1,38 milhões de professores formados em pedagogia ou com curso normal superior. Considerando-se que na década 2001 a 2010, em dez anos, portanto, foram formados 869.000 de licenciados nessas áreas, constata-se que mantido o ritmo de concluintes, o país tem condições objetivas de atender a demanda sem a necessidade de criação de novos cursos nessas áreas.

Já para o ensino médio e anos finais do ensino fundamental é fundamental construir uma matriz que leve em conta a carga horária de cada componente curricular. Isso é feito na tabela 2.

\section{Tabela 2: Matriz curricular utilizada (horas/semana)}

\begin{tabular}{|c|c|c|}
\hline & Ensino Médio & EF Anos finais \\
\hline Língua portuguesa & 3 & 4 \\
\hline Matemática & 3 & 4 \\
\hline Biologia & 2 & \\
\hline Ed. Artística & 2 & 2 \\
\hline
\end{tabular}




\begin{tabular}{|c|c|c|}
\hline Ed. Física & 2 & 2 \\
\hline Filosofia & 1 & 2 \\
\hline Física & 2 & 2 \\
\hline Geografia & 2 & 2 \\
\hline História & 2 & \\
\hline Língua estrangeira & 2 & \\
\hline Química & 1 & 4 \\
\hline Sociologia & & 22 \\
\hline Ciências & 24 & 2 \\
\hline Total & & 2 \\
\hline
\end{tabular}

Fonte: estimativa do autor

Resta agora, estimar a carga horária docente. Para tanto, tomou-se por base uma jornada semanal de 40 horas, considerando 26,6 horas em atividades em sala de aula com os estudantes, conforme a estabelece a lei $n^{\circ} 11.738 / 2008$.

Considerando o número de turmas e esta carga horária, chegou-se à tabela 3 que apresenta uma estimativa de professores considerando a matrícula de 2012.

Tabela 3: Demanda de professores para os anos finais do ensino fundamental e ensino médio - 2012 (x 1000 professores)

\begin{tabular}{|c|c|c|c|}
\hline & EF Anos finais & Ens. Médio & Total \\
\hline LínguaLíngua portuguesa & 92,6 & 38,7 & 131,3 \\
\hline LínguaLíngua estrangeira & 46,3 & 25,8 & 72,1 \\
\hline Matemática & 92,6 & 38,7 & 131,3 \\
\hline Biologia & & 25,8 & 25,8 \\
\hline Ciências & 92,6 & & 92,6 \\
\hline Física & & 25,8 & 25,8 \\
\hline Química & & 25,8 & 25,8 \\
\hline Geografia & 46,3 & 25,8 & 72,1 \\
\hline História & 46,3 & 25,8 & 72,1 \\
\hline Ed. Física & 46,3 & 25,8 & 72,1 \\
\hline Ed. Artística & 46,3 & 25,8 & 72,1 \\
\hline Filosofia & & 12,9 & 12,9 \\
\hline Sociologia & & 12,9 & 12,9 \\
\hline
\end{tabular}

Fonte: autor a partir de dados do Censo Escolar

Obs: Considerando jornada de 40h, 26,6 com os alunos 
Feita esta estimativa, resta agora comparar a demanda estimada por componente curricular com os os concluintes, o que é feito na tabela 4. Usou-se como base os concluintes no período de 1990 a 2010, correspondendo a um período de 20 anos.

Tabela 4: Comparação entre a demanda estimada de professores e concluintes (1990-2010) por componente curricular (x mil)

\begin{tabular}{|c|c|c|c|}
\hline Comp. Curricular & Demanda & Concluintes & Razão Concluintes/demanda \\
\hline Língua portuguesa & 131,3 & 325 & 2,5 \\
\hline Língua estrangeira & 72,1 & 52 & 0,7 \\
\hline Matemática & 131,3 & 147 & 1,1 \\
\hline Biologia & 25,8 & 202 & 7,8 \\
\hline Ciências* & 92,6 & 46 & 0,5 \\
\hline Física & 25,8 & 18 & 0,7 \\
\hline Química & 25,8 & 31 & 1,2 \\
\hline Geografia & 72,1 & 117 & 1,6 \\
\hline História & 72,1 & 173 & 2,4 \\
\hline Ed. Física & 72,1 & 219 & 3 \\
\hline Ed. Artística & 72,1 & 72 & 1 \\
\hline Filosofia* & 12,9 & 15 & 1,2 \\
\hline Sociologia* & 12,9 & 24 & 1,9 \\
\hline
\end{tabular}

* Período 2000 a 2001

Fontes: Os dados referentes a 1990 a 2001 foram obtidos no estudo do CNE (2007) e para o período seguinte, foram calculados pelo autor a partir da base do INEP.

Os dados da tabela 4 indicam apenas três áreas em que, aparentemente, há falta de potenciais professores: língua estrangeira, ciências, física. Diz-se aparentemente, pois no caso de línguas estrangeiras, cuja formação exigida é licenciatura em letras, área em que há um grande excedente de licenciados, o problema pode decorrer mais da forma como os dados estão sendo contabilizados, até porque o mais comum é o licenciado em letras sair com habilitação em português e uma língua estrangeira. No caso de Ciências, objetivamente não há falta, pois os licenciados em biologia (área com grande excedente de licenciados), assim como aqueles licenciados em química e em física podem lecionar esta disciplina. Historicamente, inclusive, a licenciatura em ciências era considerada uma licenciatura de qualidade inferior, o que pode estar mudando atualmente. Também historicamente, os licenciados em biologia, pelo seu maior número, representam a maioria dos professores de ciências. Resta então ainda o gargalo da física, que já melhorou, mas ainda está longe da quantidade ideal de concluintes.

Ora, o que os dados indicados até aqui apontam é que, longe do que se imagina, não há no Brasil, um problema generalizado de falta de professores formados aptos a lecionar em suas áreas de formação. $O$ problema persiste apenas em física.

Mas fica ainda uma última questão: e se além dos concluintes, fossem consideradas as vagas oferecidas, qual seria o cenário? Os dados são apresentados na tabela 5. No caso foram consideradas as vagas oferecidas no período 2001-2010, dez anos, portanto. 
Tabela 5: Comparação entre a demanda de professores por componente curricular e as vagas oferecidas no período de 2001 a 2010 na rede pública (estadual e federal) e no total (x 1000 professores)

\begin{tabular}{|c|c|c|c|}
\hline Comp. Curricular & Demanda & Vagas públicas & Vagas totais \\
\hline Língua portuguesa & 131,3 & 189 & 417 \\
\hline Língua estrangeira & 72,1 & 19 & 83 \\
\hline Matemática & 131,3 & 156 & 526 \\
\hline Biologia & 25,8 & 100 & 302 \\
\hline Ciências & 92,6 & 34 & 85 \\
\hline Física & 25,8 & 53 & 106 \\
\hline Química & 25,8 & 49 & 224 \\
\hline Geografia & 72,1 & 69 & 353 \\
\hline História & 72,1 & 98 & 442 \\
\hline Ed. Física & 72,1 & 103 & 111 \\
\hline Ed. Artística & 72,1 & 33 & 89 \\
\hline Filosofia & 12,9 & 21 & 34 \\
\hline Sociologia & 12,9 & 13 & \\
\hline
\end{tabular}

Fonte: autor a partir dos dados do INEP

Os dados apresentados na tabela 5 apontam para um outro cenário na discussão sobre a falta de professores no Brasil. Por eles pode se constatar que se todas as vagas oferecidas na última década tivessem sido preenchidas e resultado em conclusão com sucesso haveria um excedente gigantesco de professores. Mais do que isso, contata-se que em boa parte dos componentes curriculares, somente a rede pública de ensino, cuja qualidade é reconhecidamente superior à da rede privada, poderia ter atendido a toda demanda acumulada. Em física, por exemplo, área crítica como se viu, se todos os ingressantes houvessem concluído, ter-se-ia formado o dobro de professores necessários! No caso da Pedagogia (que não se encontra na tabela) o total de vagas ofertadas de 2001 a 2010 chega a absurdos 2,6 milhões! Lembrando que o tempo de aposentadoria para uma professora é de 25 anos, e de 30 para um professor.

Ou seja, mais do que estimular a criação de novas licenciaturas, em especial na rede privada de ensino, o que cabe ao governo fazer é estimular o preenchimento de todas as vagas da rede pública, o que pode ser feito através de bolsas de estudo com valores atraentes (associadas ao compromisso de futuro exercício do magistério) e zelar para que boa parte dos ingressantes conclua seu curso com sucesso.

Agora nada disso bastará se não houver uma melhora efetiva da remuneração docente, o que ainda está longe de ocorrer como mostra a tabela 6. 
Tabela 6: Brasil: Rendimento médio mensal e jornada semanal para algumas profissões (2009)

\begin{tabular}{|c|c|c|c|c|c|c|c|c|c|c|c|c|c|}
\hline \multirow{3}{*}{ 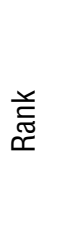 } & \multirow{3}{*}{$\begin{array}{l}\text { Ocupação no trabalho } \\
\text { principal }\end{array}$} & \multirow{3}{*}{$\stackrel{\circ}{\circ}$} & \multirow{3}{*}{$\mathrm{N}^{\mathrm{b}}$} & \multicolumn{5}{|c|}{ Rendimento ${ }^{c}$ (em R\$) } & \multicolumn{5}{|c|}{ Jornada semanal (em horas) } \\
\hline & & & & \multirow{2}{*}{ Média } & \multicolumn{2}{|c|}{$\begin{array}{l}\text { Intervalo } \\
\text { confiança }^{d}\end{array}$} & $\begin{array}{l}\text { Desvio } \\
\text { padrão }\end{array}$ & \multirow{2}{*}{ 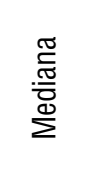 } & \multirow{2}{*}{$<30$} & \multirow{2}{*}{$\begin{array}{c}30 \mathrm{a} \\
35\end{array}$} & \multirow{2}{*}{$\begin{array}{c}36 \mathrm{a} \\
40\end{array}$} & \multirow{2}{*}{$\begin{array}{c}41 \mathrm{a} \\
44\end{array}$} & \multirow{2}{*}{$>44$} \\
\hline & & & & & $\begin{array}{l}\text { Limite } \\
\text { inferior }\end{array}$ & Limite & uperior & & & & & & \\
\hline 1 & Médicos & 1 & 220.872 & 6.140 & 5.794 & 6.486 & 3.753 & 5.100 & 9,9 & 10,8 & 22,1 & 3,9 & 53,2 \\
\hline 2 & $\begin{array}{l}\text { Professores do ensino } \\
\text { superior }\end{array}$ & 1 & 195.491 & 4.467 & 4.229 & 4.704 & 2.407 & 4.200 & 21,3 & 8,7 & 47,1 & 4,2 & 18,8 \\
\hline 3 & $\begin{array}{l}\text { Engenheiros civis e } \\
\text { afins }\end{array}$ & 1 & 116.362 & 4.428 & 4.111 & 4.744 & 2.487 & 4.000 & 5,9 & 9,2 & 45,1 & 13,7 & 26,1 \\
\hline 4 & $\begin{array}{l}\text { Fiscais de tributação e } \\
\text { arrecadação }\end{array}$ & 2 & 51.685 & 4.115 & 3.494 & 4.737 & 3.244 & 3.000 & 2,2 & 17,9 & 65,8 & 2,7 & 11,3 \\
\hline 5 & Agrônomos e afins & 1 & 32.689 & 3.683 & 3.133 & 4.233 & 2.167 & 3.400 & 11,7 & 7,0 & 59,4 & 3,1 & 18,8 \\
\hline 6 & Contadores e auditores & 1 & 285.944 & 3.602 & 3.329 & 3.876 & 3.392 & 2.400 & 3,1 & 5,3 & 52,6 & 16,8 & 22,2 \\
\hline 7 & Advogados & 1 & 429.174 & 3.583 & 3.384 & 3.782 & 2.976 & 2.700 & 13,4 & 17,5 & 38,9 & 6,6 & 23,6 \\
\hline 8 & Economistas & 1 & 93.967 & 3.570 & 3.120 & 4.021 & 3.199 & 2.500 & 1,9 & 4,8 & 63,9 & 14,5 & 15,0 \\
\hline 9 & Cirurgiões-dentistas & 1 & 149.058 & 3.450 & 3.200 & 3.700 & 2.096 & 3.000 & 13,1 & 15,8 & 35,6 & 8,5 & 27,0 \\
\hline 10 & Analistas de sistemas & 1 & 205.897 & 3.282 & 3.059 & 3.506 & 2.310 & 2.500 & 3,3 & 5,9 & 60,6 & 16,6 & 13,6 \\
\hline 11 & Administradores & 1 & 96.370 & 3.242 & 2.914 & 3.570 & 2.405 & 2.400 & 1,1 & 6,5 & 59,8 & 12,0 & 20,5 \\
\hline 12 & Arquitetos & 1 & 68.903 & 3.162 & 2.804 & 3.520 & 2.141 & 2.500 & 12,4 & 15,6 & 45,2 & 2,5 & 24,4 \\
\hline 13 & Biólogos e afins & 1 & 32.394 & 3.012 & 2.377 & 3.648 & 2.483 & 2.200 & 15,2 & 16,5 & 52,6 & 3,4 & 12,3 \\
\hline 14 & Jornalistas & 1 & 41.482 & 2.445 & 2.042 & 2.848 & 1.998 & 1.900 & 12,3 & 17,1 & 36,1 & 11,0 & 23,6 \\
\hline 15 & $\begin{array}{l}\text { Psicólogos e } \\
\text { psicanalistas }\end{array}$ & 1 & 79.006 & 2.352 & 2.142 & 2.561 & 1.364 & 2.000 & 23,6 & 16,7 & 41,5 & 5,1 & 13,1 \\
\hline 16 & Corretores de imóveis & 2 & 135.247 & 2.291 & 2.119 & 2.463 & 1.481 & 2.000 & 13,5 & 9,7 & 27,1 & 9,8 & 39,9 \\
\hline 17 & Farmacêuticos & 1 & 68.137 & 2.197 & 1.978 & 2.415 & 1.285 & 2.000 & 5,8 & 5,3 & 42,2 & 13,7 & 33,1 \\
\hline 18 & $\begin{array}{l}\text { Enfermeiros de nível } \\
\text { superior }\end{array}$ & 1 & 214.895 & 2.189 & 2.081 & 2.297 & 1.123 & 2.000 & 4,5 & 11,1 & 45,4 & 10,9 & 28,1 \\
\hline 19 & Corretores de seguro & 1 & 78.056 & 1.997 & 1.747 & 2.247 & 1.549 & 1.500 & 9,5 & 7,9 & 48,0 & 13,4 & 21,1 \\
\hline 20 & $\begin{array}{c}\text { Professores do ensino } \\
\text { médio }\end{array}$ & 1 & 395.846 & 1.916 & 1.847 & 1.985 & 1.012 & 1.700 & 23,2 & 10,8 & 41,3 & 4,2 & 20,5 \\
\hline 21 & Fisioterapeutas e afins & 1 & 99.900 & 1.826 & 1.699 & 1.953 & 908 & 1.600 & 20,7 & 21,6 & 34,0 & 4,8 & 19,0 \\
\hline 22 & $\begin{array}{l}\text { Cabos e soldados da } \\
\text { polícia militar }\end{array}$ & 3 & 268.714 & 1.744 & 1.691 & 1.797 & 668 & 1.650 & 2,0 & 3,8 & 39,2 & 9,6 & 45,4 \\
\hline 23 & Caixas de bancos & 3 & 88.628 & 1.709 & 1.567 & 1.850 & 934 & 1.500 & 1,0 & 32,9 & 51,3 & 5,7 & 9,1 \\
\hline 24 & Técnicos químicos & 2 & 54.809 & 1.664 & 1.482 & 1.845 & 952 & 1.500 & 3,3 & 4,5 & 44,9 & 27,0 & 20,3 \\
\hline 25 & $\begin{array}{l}\text { Téc. de segurança de } \\
\text { trabalho }\end{array}$ & 2 & 99.964 & 1.626 & 1.481 & 1.772 & 1.053 & 1.200 & 4,5 & 1,9 & 36,0 & 29,6 & 28,1 \\
\hline 26 & Téc. em contabilidade & 2 & 111.795 & 1.606 & 1.468 & 1.743 & 1.074 & 1.300 & 7,7 & 9,7 & 47,9 & 18,6 & 16,1 \\
\hline 27 & $\begin{array}{l}\text { Professores dos anos } \\
\text { finais ens.fundamental }\end{array}$ & 1 & 434.802 & 1.603 & 1.549 & 1.657 & 830 & 1.400 & 30,2 & 14,1 & 36,6 & 4,2 & 14,8 \\
\hline
\end{tabular}




\begin{tabular}{|c|c|c|c|c|c|c|c|c|c|c|c|c|c|}
\hline 28 & $\begin{array}{l}\text { Técnicos em } \\
\text { edificações }\end{array}$ & 2 & 31.018 & 1.590 & 1.347 & 1.833 & 1.020 & 1.300 & 4,7 & 8,0 & 41,3 & 24,0 & 22,0 \\
\hline 29 & $\begin{array}{c}\text { Assistentes sociais e } \\
\text { afins }\end{array}$ & 1 & 129.958 & 1.576 & 1.445 & 1.707 & 1.107 & 1.275 & 10,5 & 14,8 & 53,5 & 7,1 & 14,1 \\
\hline 30 & $\begin{array}{l}\text { Desenhistas e } \\
\text { modelistas }\end{array}$ & 2 & 184.972 & 1.463 & 1.345 & 1.580 & 1.128 & 1.111 & 9,0 & 6,8 & 36,3 & 21,7 & 26,2 \\
\hline 31 & $\begin{array}{l}\text { Professores dos } \\
\text { anos iniciais ens. } \\
\text { fundamental }\end{array}$ & 1 & 320.532 & 1.454 & 1.400 & 1.508 & 704 & 1.300 & 31,0 & 14,5 & 38,3 & 4,5 & 11,8 \\
\hline 32 & $\begin{array}{l}\text { Técnicos em } \\
\text { programação }\end{array}$ & 2 & 221.995 & 1.399 & 1.302 & 1.495 & 1.041 & 1.000 & 9,3 & 6,8 & 43,7 & 20,0 & 20,2 \\
\hline 33 & $\begin{array}{l}\text { Técnicos em } \\
\text { telecomunicações }\end{array}$ & 2 & 74.703 & 1.380 & 1.222 & 1.537 & 957 & 1.115 & 0,8 & 6,8 & 43,0 & 26,5 & 22,8 \\
\hline 34 & Carteiros e afins & 3 & 71.721 & 1.293 & 1.201 & 1.386 & 562 & 1.200 & 0,7 & 2,1 & 62,6 & 21,9 & 12,7 \\
\hline 35 & $\begin{array}{l}\text { Operadores de } \\
\text { computadores }\end{array}$ & 2 & 52.652 & 1.244 & 1.056 & 1.431 & 1.009 & 809 & 19,7 & 10,5 & 38,3 & 8,4 & 23,0 \\
\hline 36 & $\begin{array}{l}\text { Professores da } \\
\text { educação infantil }\end{array}$ & 1 & 107.991 & 1.208 & 1.109 & 1.307 & 702 & 995 & 30,2 & 17,2 & 40,8 & 2,2 & 9,6 \\
\hline 37 & $\begin{array}{l}\text { Técnicos de análises } \\
\text { clínicas }\end{array}$ & 2 & 47.284 & 1.156 & 1.011 & 1.300 & 707 & 879 & 12,3 & 9,6 & 46,8 & 13,5 & 17,9 \\
\hline 38 & $\begin{array}{c}\text { Motoristas de } \\
\text { transporte coletivo }\end{array}$ & 3 & 386.810 & 1.087 & 1.062 & 1.111 & 351 & 1.070 & 2,6 & 3,9 & 21,5 & 21,4 & 50,6 \\
\hline 39 & $\begin{array}{l}\text { Téc. de controle de } \\
\text { produçãa }\end{array}$ & 2 & 164.287 & 1.055 & 974 & 1.136 & 714 & 800 & 0,4 & 1,6 & 28,7 & 44,2 & 25,1 \\
\hline 40 & $\begin{array}{c}\text { Escriturários } \\
\text { e auxiliares } \\
\text { administrativos }\end{array}$ & 3 & 2.702.186 & 1.014 & 997 & 1.032 & 690 & 800 & 8,7 & 10,8 & 49,3 & 18,2 & 13,0 \\
\hline 41 & $\begin{array}{l}\text { Professores do Ens. } \\
\text { fundamental }\end{array}$ & 2 & 213.202 & 997 & 949 & 1.045 & 524 & 900 & 47,1 & 8,6 & 32,9 & 2,7 & 8,8 \\
\hline 42 & $\begin{array}{l}\text { Técnicos e auxiliares } \\
\text { de enfermagem }\end{array}$ & 2 & 574.009 & 978 & 952 & 1.003 & 462 & 850 & 5,7 & 10,1 & 42,6 & 12,4 & 29,1 \\
\hline 43 & $\begin{array}{l}\text { Vigilantes e guardas } \\
\text { de segurança }\end{array}$ & 3 & 601.183 & 881 & 861 & 901 & 373 & 800 & 2,2 & 3,5 & 34,1 & 14,4 & 45,7 \\
\hline 44 & $\begin{array}{c}\text { Vendedores em lojas } \\
\text { ou mercados }\end{array}$ & 3 & 4.956 .249 & 735 & 725 & 744 & 495 & 600 & 9,8 & 5,3 & 18,5 & 22,8 & 43,6 \\
\hline 45 & $\begin{array}{l}\text { Trabalhadores de } \\
\text { higiene e beleza }\end{array}$ & 3 & 938.650 & 722 & 700 & 743 & 485 & 600 & 30,1 & 13,2 & 17,9 & 5,1 & 33,7 \\
\hline 46 & $\begin{array}{l}\text { Professores da } \\
\text { ducação infantil }\end{array}$ & 2 & 103.438 & 702 & 662 & 743 & 313 & 610 & 40,9 & 17,2 & 33,2 & 1,8 & 6,8 \\
\hline 47 & $\begin{array}{l}\text { Agentes da saúde e } \\
\text { meio ambiente }\end{array}$ & 2 & 385.496 & 685 & 660 & 710 & 361 & 560 & 4,4 & 8,6 & 72,8 & 3,3 & 10,8 \\
\hline
\end{tabular}

Fonte: Alves e Pinto (2011)

Notas:

a. $1=$ profissionais das ciências e das artes (formação em nível superior); $2=$ técnicos de nível médio; 3 = Outros trabalhadores de nível médio

b. Estimava da população

c. Valores médios para jornadas de trabalho semanais iguais ou superiores a 30 horas expressos em $\mathrm{R} \$$. 0 salário mínimo em setembro/2009 era $\mathrm{R} \$ 465$

d. Intervalo de confiança de $95 \%$.

e. Em valores percentuais. Refere-se à distribuição da população nas faixas de jornada semanal 
Os dados da tabela 6 falam por si. E o mais grave é que com a expansão totalmente irresponsável de licenciaturas na modalidade EAD, cujos alunos são reconhecidamente menos preparados que os alunos dos cursos presenciais, a tendência é achatar ainda mais os salários, dada a grande oferta, afugentando da profissão exatamente os docentes mais bem preparados que o país tanto precisa para melhorar a qualidade de seu ensino. Qualquer política, no momento, de estímulo à expansão de vagas, em especial na modalidade EAD é um grave equívoco, com conseqüências danosas para a educação brasileira.

\section{Referências Bibliográficas}

ALVES, T.; PINTO, J.M.R. Remuneração e características do trabalho docente no Brasil: um aporte dos dados do Censo Escolar e da PNAD. Cadernos de Pesquisa (Fundação Carlos Chagas),v.41, n.143,2011.

CNE Conselho Nacional de Educação. Escassez de Professores no ensino médio. Relatório produzido pela Comissão Especial instituída para estudar medidas que visem a superar o déficit docente no Ensino Médio (CNE/CEB) Maio/2007

SAMPAIO, C.E.M et. al. Estatísticas dos professores no Brasil. Revista brasileira de estudos pedagógicos, Brasília, v. 83, n. 203/204/205, p. 85-120, jan./dez. 2002. 